\title{
An empirical DEA investigation for development of new bank's branches
}

\author{
Mousa Azarbad ${ }^{\mathrm{a}}$, Amir Reza Soltani ${ }^{\mathrm{a}^{*}}$ and Amir Abbas Shojaie ${ }^{\mathrm{b}}$
}

${ }^{a}$ PhD Candidate, School of Industrial Engineering, Islamic Azad University, South Tehran Branch, Tehran, Iran ${ }^{b}$ Assistant Professor, School of Industrial Engineering, Islamic Azad University, South Tehran Branch, Tehran, Iran

\section{H R O N I C L E}

Article history:

Received January 2, 2015

Received in revised format 6

February 2015

Accepted 24 February 2015

Available online

February 252015

Keywords:

$D E A$

Fuzzy

Efficiency

Banking industry

\begin{abstract}
A B S T R A C T
During the past few years, there have been tremendous efforts on development of Iranian banking industry in an attempt to fight against monopoly of banking system. Bank Pasargad is one of the biggest Iranian banks established for offering retail, commercial as well as investment banking services. The firm was established in 2005 as part of the government's privatization of the banking system. This paper presents an empirical investigation to determine the most efficient locations for development of this bank. The study uses three main criteria, customer services $\left(\mathrm{C}_{1}\right)$, Equipment $\left(\mathrm{C}_{2}\right)$ and Profitability $\left(\mathrm{C}_{3}\right)$ to compare different alternatives for establishing new branches in city of Tehran, Iran. Using fuzzy data envelopment analysis the study has determined that center of the city could receive the most important attraction followed by north region, west region as well as south west.
\end{abstract}

\section{Introduction}

During the past few years, there have been tremendous efforts on development of banking industry in an attempt to fight against existing monopoly in Iranian banking industry. Most banks try to develop their business activities by establishing new branches to attract more customers and retain existing customers (Isik \& Hassan, 2002; Assaf et al., 2011; Edelstein et al., 2012). Locating the best places to attract consumer plays essential role on gaining more market share in the presence of tight competition. Data envelopment analysis has been proven to be an efficient method for measuring the relative efficiencies of various banks (Avkiran, 1999; Sathye, 2001). Soteriou and Stavrinides (2000) developed a DEA model, which could be applied to provide direction for improvement to branches which would not use their resources in the most efficient way to produce service quality. They concentrated on internal customer service quality which seemed to be easier to measure and presented their results from an empirical study undertaken at a bank to show the applicability of their model. Xiaogang et al. (2005) investigated the cost, technical and allocative efficiency of 43 Chinese banks from 1993 to 2000. The objective of this analysis was to determine the change in Chinese banks' efficiency following the 
program of deregulation started by the government in 1995. They explained that the large state-owned banks and smaller banks were more efficient than medium sized Chinese banks. Moreover, technical efficiency consistently dominated the allocative efficiency of Chinese banks. The financial deregulation of 1995 was determined to improve cost efficiency levels including both technical and allocative efficiency. Wang et al. (2014) utilized the network DEA method to disaggregate, evaluate and examine the efficiencies of 16 major Chinese commercial banks during the third round of the Chinese banking reform period. Azarbad et al. (2011) presented a hybrid of DEA and balance scorecard (Kaplan \& Norton, 2005) to select commercial bank partner.

\section{The proposed study}

The proposed study of this paper uses fuzzy data envelopment analysis (DEA) to compare the performance of different alternatives for establishing new branches of banks. Fig. 1 demonstrates the structure of the proposed study.

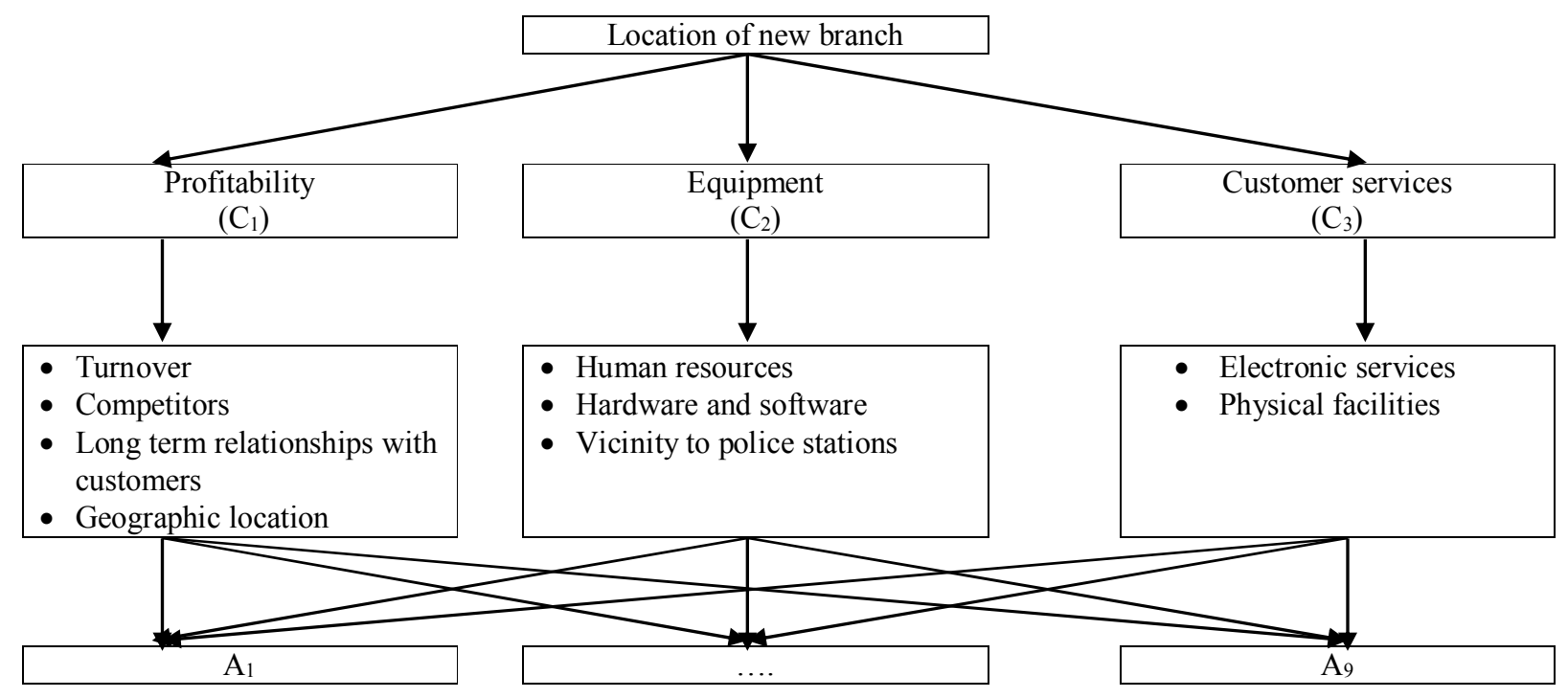

Fig. 1. The proposed study

In addition, the study uses triangular fuzzy numbers, $\tilde{A}=\left(a^{l}, a^{m}, a^{r}\right)$, shown in Fig 2 to handle any uncertainty associated with numbers.

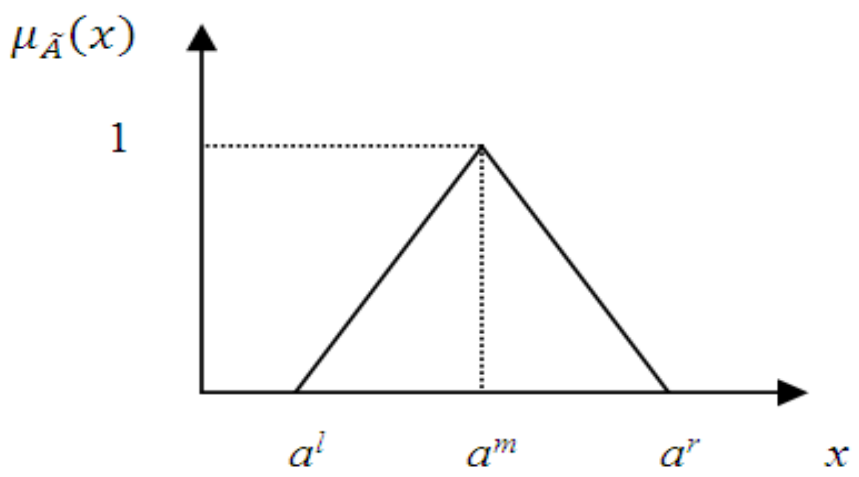

Fig. 2. Triangular fuzzy number (Zadeh, 1965, 1997)

Here membership function is defined as follows, 


$$
\mu_{\widetilde{A}}(x)=\left\{\begin{array}{cc}
\frac{x-a^{l}}{a^{m}-a^{l}}, & a^{l} \leq x \leq a^{m} \\
\frac{x-a^{r}}{a^{m}-a^{r}}, & a^{m} \leq x \leq a^{r} \\
0, & \text { otherwise }
\end{array}\right.
$$

Let $\tilde{A}$ and $\tilde{B}$ be two fuzzy numbers and the following summarize different fuzzy arithmetic,

$$
\begin{aligned}
& \widetilde{A}(+) \widetilde{B}=\left[a^{l}+b^{l}, a^{m}+b^{m}, a^{r}+b^{r}\right], \\
& \widetilde{A}(-) \widetilde{B}=\left[a^{l}-b^{l}, a^{m}-b^{m}, a^{r}-b^{r}\right], \\
& \widetilde{A}(\times) \widetilde{B} \cong\left[a^{l} b^{l}, a^{m} b^{m}, a^{r} b^{r}\right], \\
& \widetilde{A}=\left(a^{l}=\min _{k}\left\{a_{k}^{l}\right\}, a^{m}=\frac{\sum_{k=1}^{K} a_{k}^{m}}{K}, a^{r}=\max _{k}\left\{a_{k}^{r}\right\}\right),
\end{aligned}
$$

where $k$ represents the number of decision makers. Consider a fuzzy linear programming as follows, $\max \sum_{j=1}^{n}\left(C_{j}^{l}, C_{j}^{m}, C_{j}^{r}\right) x_{j}$

subject to

$\sum_{j=1}^{n}\left(a_{j}^{l}, a_{j}^{m}, a_{j}^{r}\right) x_{j} \geq\left(b^{l}, b^{m}, b^{r}\right)$,

$x_{j} \geq 0$,

According to Jiménez et al. (2007), the model can be converted as follows,

$\max \sum_{j=1}^{n} C_{j}^{m} x_{j}$

subject to

$\sum_{j=1}^{n}\left(\alpha\left(\frac{a_{j}^{l}+a_{j}^{m}}{2}\right)+(1-\alpha)\left(\frac{a_{j}^{r}+a_{j}^{m}}{2}\right)\right) x_{j} \geq \alpha\left(\frac{b^{m}+b^{r}}{2}\right)+(1-\alpha)\left(\frac{b^{l}+b^{m}}{2}\right)$,

$x_{j} \geq 0, \alpha \in[0,1]$.

Charnes et al. (1978) and Banker et al. (1984) are believed to be the first who introduced the idea of data envelopment analysis (DEA) in a form of constant return to scale (CCR) as follows,

$$
\begin{aligned}
& \max _{u, v} s_{o}=\sum_{r} u_{r} y_{r_{o}} \\
& \text { subject to } \\
& \sum_{i} v_{i} x_{i_{o}}=1, \\
& \sum_{r} u_{r} y_{r j}-\sum_{i} v_{i} x_{i j} \leq 0, \quad \forall j, \\
& x_{i j}, y_{r j} \geq 0 \quad \forall r, i, j, \\
& u_{r} \geq 0 \quad \forall r, \\
& v_{i} \geq 0 \quad \forall i .
\end{aligned}
$$


where $x_{i j}$ and $y_{r j}$ represent inputs and outputs of different units. In addition, $v_{i}$ and $u_{r}$ represent the coefficients of inputs and outputs. In addition, the fuzzy CCR model is as follows,

$$
\begin{aligned}
& \max _{u, v} z_{o}=\sum_{r} \tilde{u}_{r} y_{r_{o}} \\
& \text { subject to } \\
& \sum_{i} \tilde{v}_{i} x_{i_{o}}=1, \\
& \sum_{\mathrm{r}} \tilde{u}_{r} y_{r j}-\sum_{i} \tilde{v}_{i} x_{i j} \leq 0 \quad \forall j, \\
& y_{r o}, y_{r j} \geq 0 \quad \forall r, j, \\
& x_{i o}, x_{i j} \geq 0 \quad \forall i, j .
\end{aligned}
$$

Here $\tilde{v}_{i}=\left(v_{i}^{l}, v_{i}^{m}, v_{i}^{r}\right)$ and $\tilde{u}_{r}=\left(u_{r}^{l}, u_{r}^{m}, u_{r}^{r}\right)$ are fuzzy triangular numbers. Using Eq. (7), we have

$$
\max _{u, v} \sum_{r} u_{r}^{m} x_{r_{o}}
$$

subject to

$$
\begin{aligned}
& \sum_{i}\left(\alpha\left(\frac{v_{i}^{l}+v_{i}^{m}}{2}\right)+(1-\alpha)\left(\frac{v_{i}^{r}+v_{i}^{m}}{2}\right)\right) x_{i_{o}}=1, \\
& \sum_{i}\left(\alpha\left(\frac{u_{r}^{l}+u_{r}^{m}}{2}\right)+(1-\alpha)\left(\frac{u_{r}^{r}+u_{r}^{m}}{2}\right)\right) y_{r_{j}} \leq \sum_{i}\left(\alpha\left(\frac{v_{i}^{l}+v_{i}^{m}}{2}\right)+(1-\alpha)\left(\frac{v_{i}^{r}+v_{i}^{m}}{2}\right)\right) x_{i_{j}} \\
& y_{r o}, y_{r j} \geq 0 \quad \forall r, j, \\
& x_{i o}, x_{i j} \geq 0 \quad \forall i, j . \\
& \alpha \in[0,1] .
\end{aligned}
$$

\section{Case study}

Bank Pasargad, also known as BPI, is one of the biggest Iranian banks established for offering retail, commercial as well as investment banking services. The firm was established in 2005 as part of the government's privatization of the banking system. The bank's headquarter is in Tehran and it operates throughout the country with 3251 employees and 297 branches. In 2012, The Banker magazine rated BPI as the top " 1000 banks in the world", ranking $266^{\text {th }}$ overall. The bank tries to determine the location of some new branches in 9 different parts of the city of Tehran, Iran. The idea is to determine the most efficient places to establish new branches. The study uses three main criteria, customer services $\left(\mathrm{C}_{1}\right)$, Equipment $\left(\mathrm{C}_{2}\right)$ and Profitability $\left(\mathrm{C}_{3}\right)$ to compare different alternatives.

The first criterion, profitability, includes four sub-components including financial turnover, competition, long term relationships with customers and geographic location of each branch. The last sub-component, geographical location, is categorized into commercialized, residential, recreational, administration and transportation areas. Moreover, transportation itself includes various categories including Subway, Taxi, Bus, etc. as well as vicinity to traffic jam and places with dense population.

The second criterion, equipment, includes three sub-components of hardware/software, human resources and vicinity to security. Human resources is also categorized into executive and management. The last item, customer services, consists of two factors of electronic services and physical facilities. 
In our survey, we have used the opinions of 35 experts where 20 were top managers and 15 were regular staff. Table 1 demonstrates the summary of the triangular fuzzy numbers.

Table 1

The summary of linguistic verbs

\begin{tabular}{lccccc}
\hline Term & Very poor (VP) & Poor $(\mathrm{P})$ & Medium $(\mathrm{M})$ & Strong (S) & Very Strong (VS) \\
\hline Number & $(0,0, .2)$ & $(0.1,0.3,0.5)$ & $(0.3,0.5,0.7)$ & $(0.5,0.7,0.9)$ & $(0.8,1,1)$ \\
\hline
\end{tabular}

Based on the numbers given in Table 1, decision makers have given some points to various alternatives based on three criteria and Table 2 shows the results

Table 2

The summary of points given to various criteria

\begin{tabular}{lccc}
\hline & $\mathrm{C}_{1}$ & $\mathrm{C}_{2}$ & $\mathrm{C}_{3}$ \\
\hline $\mathrm{A}_{1}$ & $(0,0.75,1)$ & $(0.18,0.58,0.82)$ & $(0,0.22,0.62)$ \\
$\mathrm{A}_{2}$ & $(0,0.45,0.1)$ & $(0.13,0.33,0.5)$ & $(0,0.16,0.52)$ \\
$\mathrm{A}_{3}$ & $(0,0.3,1)$ & $(0,0.2,0.7)$ & $(0,0.15,0.5)$ \\
$\mathrm{A}_{4}$ & $(0,0.5,1)$ & $(0.01,0.23,0.43)$ & $(0,0.2,0.7)$ \\
$\mathrm{A}_{5}$ & $(0,0.55,1)$ & $(0.04,0.24,0.48)$ & $(0,0.2,0.7)$ \\
$\mathrm{A}_{6}$ & $(0,0.1,0.2)$ & $(0,0.7,1)$ & $(0.3,0.71,1)$ \\
$\mathrm{A}_{7}$ & $(0,0.7,1)$ & $(0,0.5,1)$ & $(0.32,0.79,1)$ \\
$\mathrm{A}_{8}$ & $(0,0.7,1)$ & $(0,0.89,0.9)$ & $(0.74,0.89,1)$ \\
$\mathrm{A}_{9}$ & $(0,0.3,0.9)$ & $(0,0.4,1)$ & $(0,0.38,0.9)$ \\
\hline
\end{tabular}

Now, we are able to use fuzzy DEA represented in Eq. (10) to rank 9 different alternatives. Table 3 demonstrates the summary of our findings.

Table 3

The summary of the results of fuzzy DEA

\begin{tabular}{ccccccccccccc}
\hline Alternative & $\alpha$ & Efficiency & Rank & $\alpha$ & Efficiency & Rank & $\alpha$ & Efficiency & Rank & $\alpha$ & Efficiency & Rank \\
\hline $\mathrm{A}_{1}$ & 0.1 & 0.913 & 2 & 0.2 & 0.923 & 2 & 0.3 & 0.932 & 3 & 0.4 & 0.942 & 3 \\
$\mathrm{~A}_{2}$ & 0.1 & 0.897 & 3 & 0.2 & 0.921 & 3 & 0.3 & 0.946 & 2 & 0.4 & 0.972 & 2 \\
$\mathrm{~A}_{3}$ & 0.1 & 0.592 & 6 & 0.2 & 0.601 & 6 & 0.3 & 0.621 & 6 & 0.4 & 0.636 & 6 \\
$\mathrm{~A}_{4}$ & 0.1 & 0.789 & 4 & 0.2 & 0.833 & 4 & 0.3 & 0.882 & 4 & 0.4 & 0.938 & 4 \\
$\mathrm{~A}_{5}$ & 0.1 & 0.011 & 9 & 0.2 & 0.001 & 9 & 0.3 & 0.009 & 8 & 0.4 & 0.009 & 8 \\
$\mathrm{~A}_{6}$ & 0.1 & 0.059 & 8 & 0.2 & 0.003 & 8 & 0.3 & 0.005 & 9 & 0.4 & 0.005 & 9 \\
$\mathrm{~A}_{7}$ & 0.1 & 0.425 & 7 & 0.2 & 0.438 & 7 & 0.3 & 0.453 & 7 & 0.4 & 0.468 & 7 \\
$\mathrm{~A}_{8}$ & 0.1 & 0.618 & 5 & 0.2 & 0.635 & 5 & 0.3 & 0.653 & 5 & 0.4 & 0.673 & 5 \\
$\mathrm{~A}_{9}$ & 0.1 & 1 & 1 & 0.2 & 1 & 1 & 0.3 & 1 & 1 & 0.4 & 1 & 1 \\
\hline
\end{tabular}

\section{Discussion and conclusion}

According to the results of Table 3, as membership function, $\alpha$, receives various numbers, there seems to be insignificant difference between the results of ranking of nine alternatives. In our survey, center of the city has received the most important attraction followed by north region, west region as well as south west. The results are consistent with our expectations since center of city is highly populated and many businesses are located in this region. Therefore, new branches may attract more customers and increase profitability. In addition, north region is the host of relatively rich people and they are considered as good target for development of bank's future activities. The results of this survey is somehow consistent with findings of Aldajani and Alfares (2009), Assaf et al. (2011) and Lin et al. (2009). 


\section{Acknowledgement}

The authors would like to thank the anonymous referees for constructive comments on earlier version of this paper.

\section{References}

Aldajani, M. A., \& Alfares, H. K. (2009). Location of banking automatic teller machines based on convolution. Computers \& Industrial Engineering, 57(4), 1194-1201.

Assaf, A. G., Barros, C. P., \& Matousek, R. (2011). Technical efficiency in Saudi banks. Expert Systems with Applications, 38(5), 5781-5786.

Avkiran, N. K. (1999). An application reference for data envelopment analysis in branch banking: helping the novice researcher. International Journal of Bank Marketing, 17(5), 206-220.

Azarbad, M., Ekhtiari, M., Sarfaraz, A., \& Abdi, F. (2011). A framework to select commercial bank partner using fuzzy BSC-DEA method. Management Science Letters, 1(4), 467-480.

Charnes, A., Cooper, W. W., \& Rhodes, E. (1978). Measuring the efficiency of decision making units. European journal of operational research, 2(6), 429-444.

Banker, R. D., Charnes, A., \& Cooper, W. W. (1984). Some models for estimating technical and scale inefficiencies in data envelopment analysis. Management science, 30(9), 1078-1092.

Edelstein, B., Paradi, J. C., Wu, A., \& Yom, P. (2012). Bank branch grouping strategy, an unusual DEA application. Journal of Service Science and Management, 5(04), 355.

Isik, I., \& Hassan, M. K. (2002). Cost and profit efficiency of the Turkish banking industry: An empirical investigation. Financial Review, 37(2), 257-279.

Jiménez, M., Arenas, M., Bilbao, A., \& Rodr1, M. V. (2007). Linear programming with fuzzy parameters: an interactive method resolution. European Journal of Operational Research, 177(3), 1599-1609.

Kaplan, R. S., \& Norton, D. P. (2005). The balanced scorecard: measures that drive performance. Harvard business review, 83(7), 172-180.

Lin, T. T., Lee, C. C., \& Chiu, T. F. (2009). Application of DEA in analyzing a bank's operating performance. Expert Systems with Applications, 36(5), 8883-8891.

Sathye, M. (2001). X-efficiency in Australian banking: An empirical investigation. Journal of Banking \& Finance, 25(3), 613-630.

Soteriou, A. C., \& Stavrinides, Y. (2000). An internal customer service quality data envelopment analysis model for bank branches. International Journal of Bank Marketing, 18(5), 246-252.

Wang, K., Huang, W., Wu, J., \& Liu, Y. N. (2014). Efficiency measures of the Chinese commercial banking system using an additive two-stage DEA. Omega,44, 5-20.

Xiaogang, C., Skully, M., \& Brown, K. (2005). Banking efficiency in China: Application of DEA to pre-and post-deregulation eras: 1993-2000. China Economic Review, 16(3), 229-245.

Zadeh, L. A. (1965). Fuzzy sets. Information and control, 8(3), 338-353.

Zadeh, L. A. (1997). Toward a theory of fuzzy information granulation and its centrality in human reasoning and fuzzy logic. Fuzzy sets and systems, 90(2), 111-127. 